\title{
Time for a change?
}

\author{
Derek Richards \\ Editor, Evidence-based Dentistry
}

British Dental Association (BDA) members have received the Evidence-based Dentistry journal (EBD) as a member benefit since the first issue was provided as a supplement to the British Dental Journal (BDJ). These BDA members (and hopefully readers) will notice a significant change in their EBD from this issue: it will now be presented as an integral part of their BDJ. Those who subscribe only to EBD, whether in the UK or abroad, should continue to receive their EBD as a standalone journal with some minor cosmetic changes (eg, a different page size).

One of the aims of these changes is to raise the profile of the EBD journal in the UK, and the editorial board will be keen to see if this is achieved. Another benefit is that printing EBD within the BDJ means that EBD will now be available to student members of the BDA. Our readership is important to us so we are interested to hear your views on these changes.

It was also interesting to note that the first editorial of the new year in The Lancet $^{1}$ addressed oral health. It is good to see that the subject, an important if sadly neglected area of global health, was being highlighted in one of the core healthcare journals even if it was a little disparaging of the dental profession's advocacy in promoting good oral health.

There is more than a little justification for the view that dentists have focussed on treatment more than prevention. Nevertheless, public health dentists in many countries, along with national and international dental organisations [such as the International Association for Dental Research, European Association of Dental Public Health, the British Association for the Study of Community Dentistry and the World Health Organization(WHO)] have recently produced the Liverpool Declaration (www.who.int/oral_health/ events/liverpool_declaration/en/index. html), outlining areas that should be strengthened, by the year 2020, in order to improve oral health:
- Countries should ensure that the population has access to clean water, proper sanitation facilities, a healthy diet, and good nutrition.

- Countries should ensure appropriate and affordable fluoride programmes for the prevention of tooth decay.

- Countries should provide evidence-based programmes for the promotion of healthy lifestyles and the reduction of modifiable risk factors common to oral and general chronic diseases.

- The school should be used as a platform for promotion of health, quality of life and disease prevention in children and young people, involving families and communities.

- Countries should ensure access to primary oral health care with emphasis on prevention and health promotion.

- Countries should strengthen promotion of oral health for the growing numbers of older people, aiming at improving their quality of life.

- Countries should formulate policies for oral health as an integral part of national health programmes.

- Countries should support public health research and specifically consider the recommendations of the $\mathrm{WHO}$, which recommends $10 \%$ of a total health promotion programme budget be devoted to programme evaluation.

- Countries should establish health information systems that evaluate oral health and programme implementation, support the development of the evidence base in health promotion and disease prevention through research, and support the international dissemination of research findings.

The 9th World Congress on Preventive Dentistry will take place in Phuket, Thailand, this September, in parallel with the increasing efforts to shift the balance towards prevention in low- and middle-income and developed countries. The Childsmile Programme (www.child-smile.org) in Scotland, Forsyth
Kids (www.forsyth.org/kids/) in the US, and programmes in the Philippines (highlighted in The Lancet; www.inwent.org/ez/articles/082726/index.en.shtml), are just a few examples of the evidence-based, cost-effective preventive dentistry approaches that we have highlighted in this journal over the years. ${ }^{2}$ To me, it seems that major challenges remain, in seeking to change existing professional attitudes, health policy and funding systems so that these simple and effective interventions become the norm in everyday practice, as well as in structured programmes, to help reduce the morbidity associated with poor oral health.

By the time this editorial is published, the South Central Strategic Health Authority in the UK should have announced its decision regarding the Southampton fluoridation scheme, following the statutory public consultation. Barry Cockcroft, chief dental officer for England, said defeat in Southampton "would be disappointing" but would not stop other authorities investigating the idea. Many people believe, however, that others areas in the UK contemplating fluoridation would be unlikely to proceed if the Southampton proposal does not proceed. Although fluoridation would undoubtedly prevent caries in Southampton, as it does in the other areas where fluoride either occurs naturally or has been added to water, it is important not just to focus on this particular preventive approach: the evidence does show additional beneficial effects with topical measures (toothbrushing, varnishes and rinsing etc). Dental caries is one of the most prevalent chronic diseases of people worldwide, but it is preventable, can be arrested, and can potentially be reversed in its early stages. What's more, we know how to do it, so it's about time that we all got involved.

1. Anon. Oral health: prevention is key. Lancet 2009; 373 (9657): 1.

2. Richards D. Caries prevention guidelines. Evid Based Dent 2008; 9: 66. 